\title{
Effect of Alkaline Etching on the Inhibition of the Acidic Corrosion of Aluminum by Lupine Extract
}

\author{
B.A. Abd-El-Naby, ${ }^{a}$ O.A. Abdullatef ${ }^{b,{ }^{*}}$ H.M. El-Kshlan, ${ }^{c}$ E. Khamis, ${ }^{d}$ M.A. \\ Abd-El-Fatah ${ }^{c}$ \\ ${ }^{a}$ Faculty of Science, Chemistry Department, Alexandria University, P.O.Box 426, Alexandria \\ 21321, Egypt \\ ${ }^{b}$ Pharos University, Faculty of Pharmacy, Kanal Elmahmodia Street, Smoha, \\ Alexandria, Egypt \\ ${ }^{c}$ Faculty of Education, Alexandria University, Alexandria, Egypt \\ ${ }^{d}$ City of Scientific Research \& Technological Applications, New Borg El-Arab City, P.O. Box: \\ 21934 Alexandria, Egypt
}

Received 23 September 2014; accepted 15 February 2015

\begin{abstract}
The inhibitive effect of Lupine extract on the corrosion of etched and non-etched aluminum in aqueous solution of $0.1 \mathrm{M} \mathrm{HCl}$ was investigated at $30{ }^{\circ} \mathrm{C}$ by potentiodynamic polarization, electrochemical impedance spectroscopy (EIS) and optical microscopic techniques. Potentiodynamic polarization curves indicated that Lupine extract acts as anodic type inhibitor. EIS measurements showed that the charge transfer resistance and consequently the inhibition efficiency increase with increasing concentration of Lupine. The experimental data indicated that Lupine is more efficient as inhibitor for the acid corrosion of non-etched aluminum. The inhibitive effect of the extract was assumed to occur via adsorption of active ingredients of the extract on the metal surface. Theoretical fitting of the data to the Kinetic-thermodynamic model were tested to clarify the nature of adsorption. The optical micrographs obtained after surface pre-treatment show that alkaline etching reveals the surface to be porous-like in structure and both the acid and extract have limited effect on the size of pores.
\end{abstract}

Keywords: corrosion, adsorption, etching, electrochemical techniques, optical microscopy.

\section{Introduction}

Aluminum is an important metal because of its corrosion resistance due to the presence of a thin, adherent and protective oxide film. Aluminum and its alloys

\footnotetext{
* Corresponding author. E-mail address: ossama_abdullatef@yahoo.com
} 
are widely used in many industries such as reaction vessels, pipes, machinery and chemical batteries. Hydrochloric acid solutions are used for pickling, chemical and electrochemical etching of aluminum. Corrosion inhibitors for aluminum should be used, because the solubility of the oxide film increases, above and below $\mathrm{pH}$ 4-9 range [1] and aluminum exhibits uniform attack. Inhibitors are used to prevent metal dissolution. Most of the efficient acid inhibitors are organic compounds that contain mainly nitrogen, sulphur or oxygen atoms in their structure. Although there is a large number of organic compounds, developing new organic corrosion inhibitors is always under study [2-4]. However, many of these inhibitors are toxic and expensive. Therefore, the investigation of new ecofriendly inhibitors is essential to get over this problem, and it has been addressing toward the goal of using cheap, effective compounds at a low or "zero" environmental impact. Plant extracts are low-cost and biodegradable, and so the study of plant extracts as corrosion inhibitors has received more and more attention due to both economic and environmental benefits [5]. In 1972, El Hosary et al. [6] reported that the aqueous extract of Hibiscus subdariffa was a good inhibitor for aluminum in $2.0 \mathrm{M} \mathrm{HCl}$. Recently, some plant extracts of Vernonia amygdalina [7], Ocimum basilicum [8], Opuntia [9], Sansevieria Trifasciata [10] and Raphia hookeri [11] have been studied as corrosion inhibitors for aluminum in $\mathrm{HCl}$ solution. The inhibition efficiency of these inhibitors is normally due to the presence in their composition of complex organic species such as tannins, alkaloids, nitrogen bases, carbohydrates, amino acids and proteins.

Seeds of lupine contain up to $50 \%$ proteins, $20 \%$ lipids and $5 \%$ quinolizidine alkaloids. Analysis of the alkaloid contents by gas chromatography clarified that lupanine was the most abundant quinolizidine alkaloids; multiflorine, albine and sparteine were also present $[12,13]$. Effect of lupine on the corrosion of steel in $0.5 \mathrm{M} \mathrm{Na}_{2} \mathrm{SO}_{4}$ solution free from and containing 0.01 or $0.1 \mathrm{M} \mathrm{NaCl}$ was examined by potentiodynamic and electrochemical impedance spectroscopy techniques. Potentiodynamic polarization curves measurements indicated that lupine extract behaves as an anodic type inhibitor [14]. Effect of lupine on the corrosion of zinc in neutral, alkaline and acidic media was examined by potentiodynamic and electrochemical impedance spectroscopy techniques. Nyquist impedance plots showed that the charge transfer resistance and consequently the inhibition efficiency increase with increasing concentration of lupine [15-17].

Many chemical compositions are always used for chemical and electrochemical etching and pickling of aluminum. Higher caustic concentrations and temperatures accelerate the pickling process of aluminum but as a result, the pickled surface becomes rougher. Strongly corroding cleaners, usually on the basis of caustic soda, are applied if there is a thick oxide skin, or if much degreasing has to be done. Hardly corroding or non-corroding cleaners based on silicates and carbonates are used if there are only small amounts of grease or oil on the aluminum surface [18]. The aim of this work is to study: (1) the inhibition characteristics of Lupine extract for the acidic corrosion of aluminum and (2) the effect of alkaline etching on the inhibition efficiency of the extract. 


\section{Experimental \\ Electrochemical tests}

Electrochemical impedance and polarization curves measurements were achieved using ACM 604 Instrument. The frequency range for EIS measurements was $0.01 \leq \mathrm{f} \leq 3 \times 10^{4} \mathrm{~Hz}$ with applied potential signal amplitude of $10 \mathrm{mV}$ around the rest potential. Polarization curves measurements were carried out at scan rate $20 \mathrm{mV} / \mathrm{min}$. The data were obtained in a three electrode mode; graphite rod and saturated calomel electrode were used as counter and reference electrodes. The specimens used for constructing the working electrode were aluminum rods that had the following chemical composition (wt. \%): Al 99.687; Mn 0.001; Zn 0.001; Ni 0.001; Ti 0.003; Fe 0.171; Si 0.135; Cu 0.001. The aluminum samples were fixed in poly tetrafluoro ethylene (PTFE) rods by an epoxy resin in such a way that only one surface was left uncovered. The exposed area $\left(0.786 \mathrm{~cm}^{2}\right)$ was mechanically polished with a series of emery papers of variable grades, the samples were then washed thoroughly with distilled water followed by analytical grade ethanol and finally with distilled water, just before insertion in the cell. Measurements were done at $30^{\circ} \mathrm{C}$.

\section{Optical microscopic examination}

Optical micrographs have been taken by using an Euromex optical microscope with color video camera that is connected to a personal computer.

\section{Alkaline etching solution}

Etching process is carried out after electrodes polishing. The alkaline solution used for etching is composed of 15 g.L ${ }^{-1} \mathrm{Na}_{2} \mathrm{CO}_{3}+15$ g. $\mathrm{L}^{-1} \mathrm{Na}_{3} \mathrm{PO}_{4}$ [19]. It was conducted at $80-85{ }^{\circ} \mathrm{C}$ for 30 seconds. This was followed by rinsing with distilled water and drying prior to immersion in the polarization cell.

\section{Plants}

Lupine was used in this study as a natural inhibitor. Lupine is used for treatment of anorexia and diabetes. Its chemical composition is represented in Fig. 1.

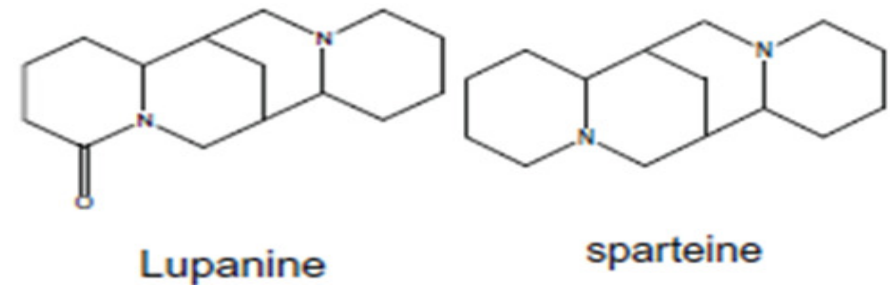<smiles>O=C1C=CN2CC3CC(CN4CCCCC34)C2C1</smiles>

Figure 1. Chemical composition of Lupine.

\section{Preparation of lupine extract}

Stock solution of Lupine was extracted by refluxing $5 \mathrm{~g}$ of the dry material in $250 \mathrm{~mL}$ distilled water for one hour. The refluxed solution was filtrated to remove any contamination. The concentration of the stock solution was calculated in $\mathrm{g} . \mathrm{L}^{-1}$ by heating till dryness $5 \mathrm{~mL}$ of the stock solution and reweight 
after drying. The concentration of the stock solution was expressed in terms of ppm.

\section{Preparation of the test solutions}

Double distilled water and analytical reagent-grade $\mathrm{HCl}(37 \%)$ were used for preparing solutions. Prior each experiment, $1.0 \mathrm{M} \mathrm{HCl}$ is added to an appropriate volume of the stock solution of the lupine extract and double distilled water to obtain solution of $0.1 \mathrm{M} \mathrm{HCl}$ and the required concentration of the extract.

\section{Results and discussion}

The effect of lupine as corrosion inhibitor for etched and non-etched aluminum in $0.1 \mathrm{M}$ solution of $\mathrm{HCl}$ has been studied using potentiodynamic polarization, electrochemical impedance spectroscopy and optical microscopy techniques.

\section{Potentiodynamic polarization results}

Fig. 2 shows the influence of lupine on the polarization curves of non-etched aluminum in $0.1 \mathrm{M} \mathrm{HCl}$ solution; it was found to be similar to that obtained for non-etched aluminum.

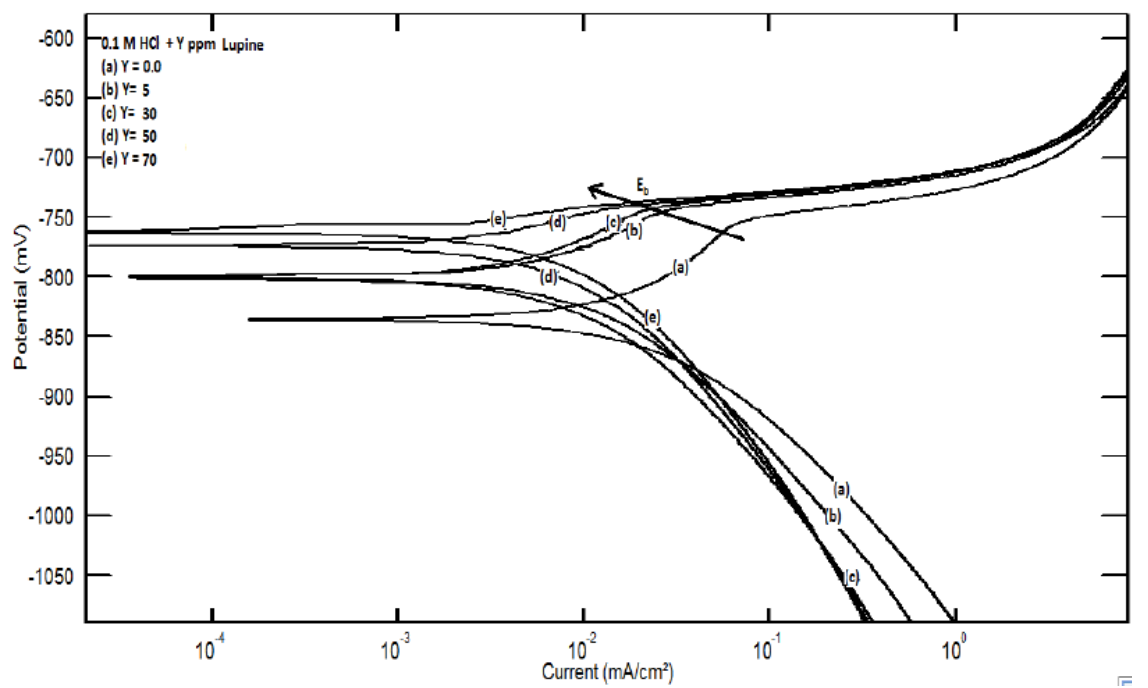

Figure 2. Potentiodynamic polarization curves for non-etched aluminum in $0.1 \mathrm{M} \mathrm{HCl}$ solution in absence and presence of different concentrations of lupine extract.

The values of the corrosion current density $\left(i_{\text {corr }}\right)$ for the etched and non-etched aluminum without and with the inhibitor were determined by the extrapolation of cathodic and anodic Tafel lines to the corrosion potential $\left(\mathrm{E}_{\mathrm{corr}}\right)$. It is clear from the potentiodynamic polarization curves that the anodic curves showed activation behavior followed by break down potential $\mathrm{E}_{\mathrm{b}}$ in absence and presence of the plant extract, indicating pitting corrosion as a result of the aggressive attack of $\mathrm{Cl}^{-}$anions. Halides, particularly chloride ions, are destructive to passivity and usually should be avoided whenever it is essential that passivity be retained. Passivity is broken down by chloride ions at point or local areas. The local areas of active metal become anodes in cells, and the cathodes of which are large areas 
of passive metal. Passivity breakdown and initiation of pitting are evident by a sudden increase in the current density at $\mathrm{E}_{\mathrm{b}}$ [20]. The anodic polarization curves show that the presence of the extract leads to a shift in the value of $E_{b}$ to more noble values. This means that the extract retards the pitting corrosion of aluminum. The potentiodynamic polarization parameters and the inhibition efficiency $\% \mathrm{P}$, which is calculated by the following equation:

$$
\% \mathrm{P}=\left[\left(\left(\mathrm{i}_{\text {corr }}\right)_{0}-\mathrm{i}_{\text {corr }}\right) /\left(\mathrm{i}_{\text {corr }}\right)_{0}\right] \times 100
$$

are presented in Tables 1 and 2.

Table 1. Values of the polarization parameters for non-etched aluminum in $0.1 \mathrm{M} \mathrm{HCl}$ solution in the absence and presence of different concentrations of lupine extract at 30 ${ }^{\circ} \mathrm{C}$.

\begin{tabular}{||c||c||c|c||c||c||}
\hline \hline $\begin{array}{c}\text { Conc. } \\
(\mathbf{p p m})\end{array}$ & $\begin{array}{c}\mathbf{E}_{\text {corr }} \\
(\mathbf{m V})\end{array}$ & $\begin{array}{c}\boldsymbol{\beta}_{\mathbf{a}} \\
(\mathbf{m V} / \mathbf{d e c a d e})\end{array}$ & $\begin{array}{c}\boldsymbol{\beta}_{\mathbf{c}} \\
(\mathbf{m V} / \mathbf{d e c a d e})\end{array}$ & $\begin{array}{c}\mathbf{i}_{\text {corr }} \\
\left(\mathbf{m A . c m} \mathbf{A m}^{-2}\right.\end{array}$ & $\mathbf{\%} \mathbf{P}$ \\
\hline \hline $\mathbf{0 . 0}$ & -792 & 136.8 & 203.64 & 0.0339 & ------ \\
\hline $\mathbf{5}$ & -763 & 76.50 & 206.84 & 0.0158 & 53.5 \\
\hline $\mathbf{1 0}$ & -756 & 83.92 & 226.76 & 0.0140 & 58.7 \\
\hline $\mathbf{3 0}$ & -755 & 65.53 & 236.21 & 0.0138 & 59.3 \\
\hline \hline $\mathbf{5 0}$ & -743 & 16.35 & 242.46 & 0.0128 & 62.2 \\
\hline \hline $\mathbf{7 0}$ & -739 & 12.55 & 243.40 & 0.0125 & 63.1 \\
\hline
\end{tabular}

Table 2. Values of the polarization parameters for etched aluminum in $0.1 \mathrm{M} \mathrm{HCl}$ solution in the absence and presence of different concentrations of lupine extract at 30 ${ }^{\circ} \mathrm{C}$.

\begin{tabular}{||c||c||c||c||c|c||}
\hline \hline $\begin{array}{c}\text { Conc. } \\
(\mathbf{p p m})\end{array}$ & $\begin{array}{c}\mathbf{E}_{\text {corr }} \\
(\mathbf{m V})\end{array}$ & $\begin{array}{c}\boldsymbol{\beta}_{\mathbf{a}} \\
(\mathbf{m V / d e c a d e})\end{array}$ & $\begin{array}{c}\boldsymbol{\beta}_{\mathbf{c}} \\
(\mathbf{m V / d e c a d e})\end{array}$ & $\begin{array}{c}\mathbf{i}_{\text {corr }} \\
\left(\mathbf{m A . c m} \mathbf{- n}^{-2}\right.\end{array}$ & $\mathbf{\%} \mathbf{P}$ \\
\hline \hline 0.0 & -795 & 110.58 & 113.7 & 0.0176 & ----- \\
\hline 10 & -816 & 112.37 & 114.25 & 0.0169 & 4.4 \\
\hline 30 & -805 & 129.72 & 120.66 & 0.0148 & 15.8 \\
\hline 50 & -794 & 132.6 & 135.21 & 0.0127 & 27.8 \\
\hline 60 & -774 & 110.99 & 145.09 & 0.0115 & 34.6 \\
\hline 100 & -759 & 18.797 & 151.47 & 0.0111 & 37.0 \\
\hline \hline 150 & -755 & 11.459 & 161.91 & 0.0098 & 44.4 \\
\hline
\end{tabular}

It can be seen that the presence of lupine shifts the corrosion potential $\left(\mathrm{E}_{\text {corr }}\right)$ towards less negative values, indicating that this extract acts predominantly as an anodic inhibitor. Consequently, the adsorption of the extract ingredients is more likely acting at the anodic sites. The data in tables 1 and 2 exhibited that the corrosion current density ( $i_{\text {corr }}$ ) decreases, and the inhibition efficiency increases as the concentration of plant extract is increased. The slope of the cathodic Tafel line $(\beta \mathrm{c})$ remains almost unchanged upon addition of the extract, indicating that the cathodic reaction which is the reduction of hydrogen ions not affected by the presence of extract and this step is controlled by charge transfer. On the other hand, the slope of the anodic Tafel line $(\beta a)$ in presence of lupine, for both etched and non-etched aluminum, decreases by increasing the extract concentration and 
a large decrease is shown in presence of high concentrations of the extract. This behavior indicates that the oxidation of aluminum in absence and presence of small concentrations of the extract is charge transfer controlled and the Tafel equation is applicable, while, in presence of high extract concentrations, oxidation of aluminum is controlled by the pitting corrosion and Tafel equation is not applicable.

\section{Electrochemical impedance spectroscopy results}

Fig. 3 represents Nyquist plots for non-etched aluminum in $0.1 \mathrm{M} \mathrm{HCl}$ solution in the absence and presence of different concentrations of lupine extract. The influence of lupine on the Nyquist plots of etched aluminum in $0.1 \mathrm{M} \mathrm{HCl}$ solution was found to be similar to that obtained for non-etched aluminum. The figure manifested only one capacitive semicircle. The diameter of the semicircle increases with increasing the extract concentration. The impedance spectra for different Nyquist plots were analyzed by fitting the experimental data using Zsimpwin program to a simple equivalent circuit model represented in Fig. 4.

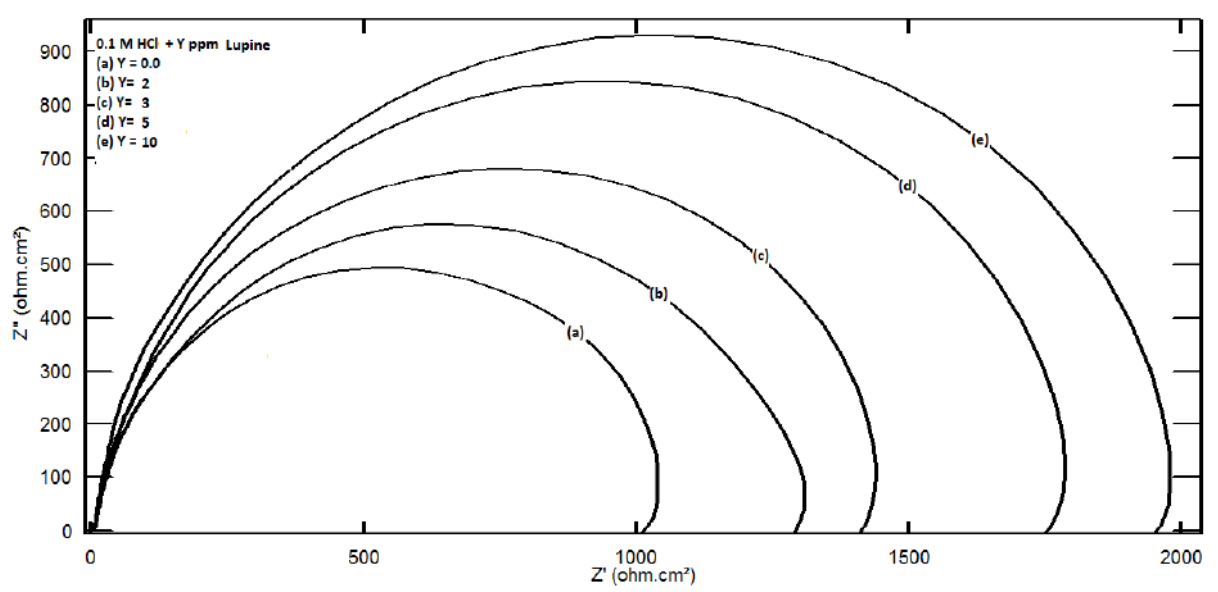

Figure 3. Nyquist plots for non-etched aluminum in $0.1 \mathrm{M} \mathrm{HCl}$ solution in absence and presence of different concentrations of lupine extract.

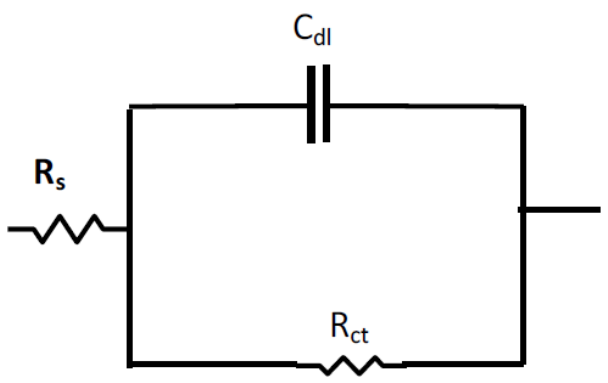

Figure 4. The equivalent circuit model.

The equivalent circuit model includes the solution resistance $\mathrm{R}_{\mathrm{s}}$ and the double layer capacitance $C_{d l}$ which is placed in parallel to the charge transfer resistance element $R_{\mathrm{ct}}$. The values of the electrochemical parameters and the inhibition efficiency ( $\%$ P) obtained from EIS for etched and non-etched aluminum in 0.1 $\mathrm{M} \mathrm{HCl}$ solutions containing different lupine extract concentrations are given in 
Tables 3 and 4. Inhibition efficiency was calculated from impedance measurements using the relation:

$$
\% \mathrm{P}=\left[\left(\mathrm{R}_{\mathrm{ct}}-\mathrm{R}_{\mathrm{ct} 0}\right) / \mathrm{R}_{\mathrm{ct}}\right] \times 100
$$

where $R_{c t 0}$ and $R_{c t}$ are the charge transfer resistances in the absence and presence of different extracts, respectively.

Table 3. Values of the impedance parameters for non-etched aluminum in $0.1 \mathrm{M} \mathrm{HCl}$ solution in the absence and presence of different concentrations of lupine extract at 30 ${ }^{\circ} \mathrm{C}$.

\begin{tabular}{|c||c||c||c|c||}
\hline $\begin{array}{c}\text { Conc. } \\
(\mathbf{p p m})\end{array}$ & $\begin{array}{c}\mathbf{R}_{\mathbf{s}} \\
\left(\mathbf{O h m . c m}^{\mathbf{2}}\right)\end{array}$ & $\begin{array}{c}\mathbf{C} \\
\left(\boldsymbol{\mu} \mathbf{F} . \mathbf{c m}^{-\mathbf{1}}\right)\end{array}$ & $\begin{array}{c}\mathbf{R}_{\mathbf{c t}} \\
\left(\mathbf{O h m . c m}^{2}\right)\end{array}$ & $\mathbf{\%} \mathbf{P}$ \\
\hline \hline $\mathbf{0 . 0}$ & 7.57 & 13.53 & 1006 & ----- \\
\hline $\mathbf{2}$ & 7.79 & 9.15 & 1225 & 17.9 \\
\hline $\mathbf{3}$ & 7.24 & 11.18 & 1387 & 27.5 \\
\hline \hline $\mathbf{5}$ & 6.71 & 10.46 & 1728 & 41.8 \\
\hline \hline $\mathbf{1 0}$ & 6.66 & 10.12 & 1913 & 47.4 \\
\hline \hline $\mathbf{1 5}$ & 6.62 & 9.95 & 2060 & 51.2 \\
\hline \hline $\mathbf{2 0}$ & 6.82 & 9.77 & 2333 & 56.9 \\
\hline $\mathbf{3 0}$ & 6.90 & 9.40 & 2657 & 62.1 \\
\hline \hline $\mathbf{5 0}$ & 6.84 & 9.71 & 2966 & 66.1 \\
\hline \hline $\mathbf{7 0}$ & 7.08 & 9.53 & 3259 & 69.2 \\
\hline \hline $\mathbf{8 0}$ & 6.91 & 8.94 & 3572 & 71.9 \\
\hline \hline $\mathbf{1 0 0}$ & 6.92 & 9.48 & 3514 & 71.4 \\
\hline
\end{tabular}

Table 4. Values of the electrochemical impedance parameters for etched aluminum in $0.1 \mathrm{M} \mathrm{HCl}$ solution in the absence and presence of different concentrations of lupine extract at $30^{\circ} \mathrm{C}$.

\begin{tabular}{|c|c|c|c|c|}
\hline $\begin{array}{l}\text { Conc. } \\
\text { (ppm) }\end{array}$ & $\underset{\left(\mathbf{O h m} \cdot \mathbf{c m}^{2}\right)}{\mathbf{R}_{\mathrm{s}}}$ & $\underset{\left(\mu \mathbf{F} . \mathrm{cm}^{-1}\right)}{C}$ & $\begin{array}{c}\mathbf{R}_{\mathrm{ct}} \\
\left(\mathbf{O h m} \cdot \mathrm{cm}^{2}\right)\end{array}$ & $\% \mathrm{P}$ \\
\hline 0.0 & 6.26 & 19.79 & 794.2 & " \\
\hline 10 & 6.32 & 20.64 & 859.1 & 7.6 \\
\hline 30 & 6.45 & 18.75 & 988.2 & 19.6 \\
\hline 50 & 10.21 & 19.25 & 1116 & 28.8 \\
\hline 100 & 8.53 & 20.74 & 1282 & 38.0 \\
\hline 150 & 7.94 & 20.18 & 1366 & 41.9 \\
\hline 200 & 6.49 & 18.08 & 1549 & 48.7 \\
\hline 300 & 7.93 & 20.96 & 1388 & 42.8 \\
\hline
\end{tabular}

The results show that $R_{c t}$ values for etched and non-etched aluminum increase with increasing the lupine extract concentration. The increase of $R_{c t}$ values suggests the formation of a protective layer on the electrode surface. This layer acts as a barrier for mass and charge transfer [21-23]. The capacitance of the double layer $\mathrm{C}_{\mathrm{dl}}$ decreases with increasing the concentration of the extract in the case of non-etched aluminum and not affected by the presence or the 
concentration of the extract in the case of etched aluminum; this can be explained due to the weak adsorption of extract ingredients in the case of etched aluminum.

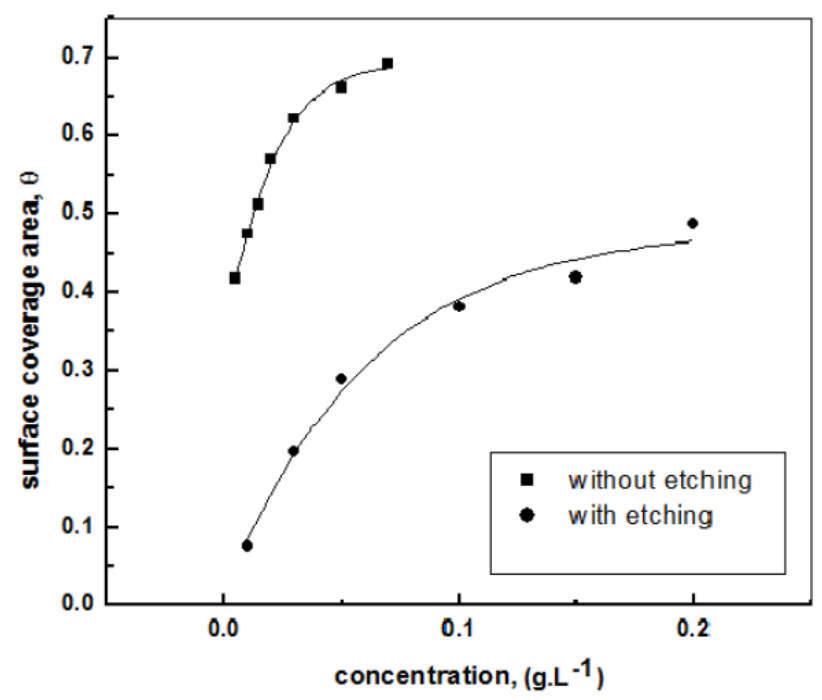

Figure 5. Variations of the degree of surface coverage on etched and non-etched aluminium in $0.1 \mathrm{M} \mathrm{HCl}$ solution with concentration of lupine extract.

\section{Adsorption mechanism}

The nature of the adsorption process of the extract on the etched and non-etched aluminum metal surface was essential to our knowledge of their inhibition action to corrosion. The variation of degree of surface coverage $\theta$ with concentration of lupine plant extract is shown in Fig. 5. This plot is characterized by an initial steeply rising part indicating the formation of a mono-layer adsorbate film on the aluminum surface. At high concentrations, the inhibitory effect was constant suggesting complete saturation of the surface by the inhibitor molecules.

The action of adsorptive inhibitors was studied by Elawady et al. [24] under pseudo zero order conditions and the mathematical expression was given as:

$$
\log [\theta /(1-\theta)]=\log \mathrm{K}^{\prime}+\mathrm{y} \log [\mathrm{I}]
$$

where $\theta$ is the degree of surface coverage by the inhibitor, $(1-\theta)$ is the fraction of the surface available for medium attack, $y$ is the number of inhibitor molecules occupying one active site. The value, 1/y represents the number of active sites of the surface occupied by one inhibitor molecule. Value of $1 / y$ less than unity implies the formation of multilayer of the inhibitor on the surface of the metal. However, values of $1 / y$ greater than unity indicate that a given inhibitor molecule will occupy more than one active site [25]. The binding constant $K$ corresponding to that obtained from the adsorption isotherm curve fitting is given by:

$$
\mathrm{K}=\mathrm{K}^{\prime}(1 / \mathrm{y})
$$

Fig. 6 shows the application of the kinetic-thermodynamic model to the results of adsorption of the extract on etched and non-etched aluminum surface. 


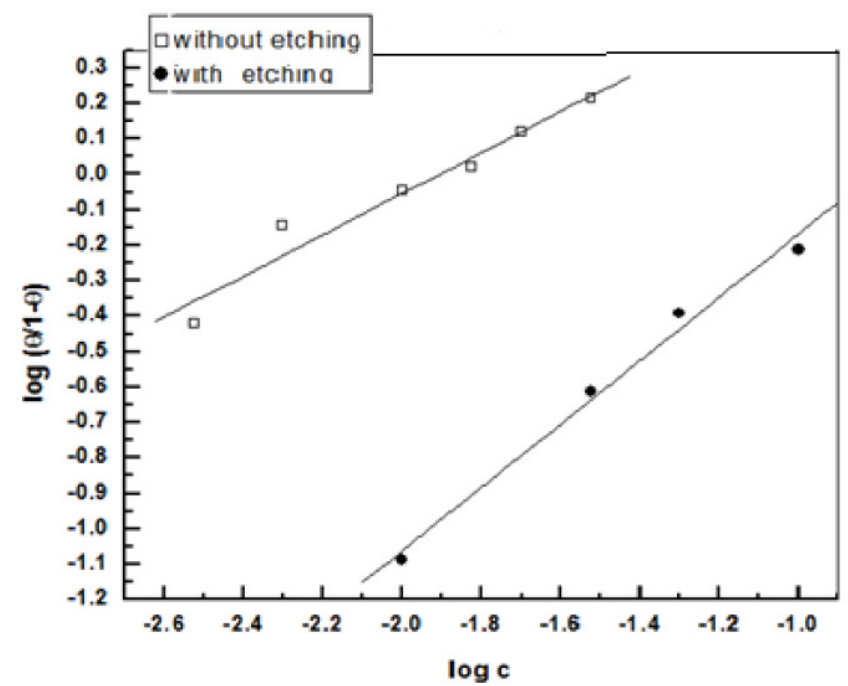

Figure 6. Application of the kinetic-thermodynamic model to the results of adsorption of lupine extract in $0.1 \mathrm{M} \mathrm{HCl}$ solution on etched and non-etched aluminum surface.

The kinetic-thermodynamic model was found to fit the data of lupine plant extract for both etched and non-etched aluminum in $0.1 \mathrm{M} \mathrm{HCl}$ and the linear fitting parameters are given in Table 5. The number of active sites occupied by a single inhibitor molecule, $1 / \mathrm{y}$, was nearly equal to one for etched aluminum, indicating that each inhibitor molecule can occupy only one active site on the aluminum surface, while $1 / y$ were more than one for non-etched aluminum, indicating that each inhibitor molecule can occupy more than one active site on the aluminum surface. The numerical values of $\mathrm{K}$ indicate that there is a strong adsorption of the lupine active ingredients on to the non-etched aluminum surface compared to the etched aluminum.

Table 5. Linear fitting parameters of lupine extract according to the kineticthermodynamic model for etched and non-etched aluminum in $0.1 \mathrm{M} \mathrm{HCl}$.

\begin{tabular}{|c|c|c|c|}
\hline \multicolumn{4}{|c|}{ Model parameters } \\
\hline \multicolumn{2}{|c|}{ (without etching) } & \multicolumn{2}{c|}{ (with etching ) } \\
\hline K & $\mathbf{1 / y}$ & $\mathbf{K}$ & $\mathbf{1 / y}$ \\
\hline 80.3 & 1.7 & 6.5 & 1.1 \\
\hline
\end{tabular}

\section{Optical microscopic results}

Optical microscopy studies of the etched and non-etched aluminum surface in absence and presence of Lupine extract in $0.1 \mathrm{M} \mathrm{HCl}$ are seen in Fig. 7. A(a, b, c) and $\mathrm{B}(\mathrm{a}, \mathrm{b}, \mathrm{c})$, where $\mathrm{A}$ for the non-etched aluminum surface and $\mathrm{B}$ for the etched one, "a" before dipping in acid, "b" after dipping in $0.1 \mathrm{M} \mathrm{HCl}$ for one hour and "c" after dipping in $0.1 \mathrm{M} \mathrm{HCl}$ containing $50 \mathrm{ppm}$ of lupine extract for one hour. The magnification was 40 times. The surface photographs for nonetched aluminum (A) have clearly visible polishing marks on the surface either before or after dipping in acid free or acid containing the extract. The photographs obtained after surface pre-treatment by alkaline etching (B) indicated that the etching process reveals the surface to be porous-like in structure and both the acid and extract has limited effect on the size of pores. 
These results indicate that the number of the active sites of the etched aluminum surface is less than those for non-etched one [26]. The photographs (C) indicate that the extract can adsorb on the metal surface in the case of non-etched aluminum. This argument explains the data obtained from the polarization and impedance measurements which indicate that the inhibition efficiency and the value of the binding constant $\mathrm{K}$ of the extract is higher in the case of non-etched aluminum.

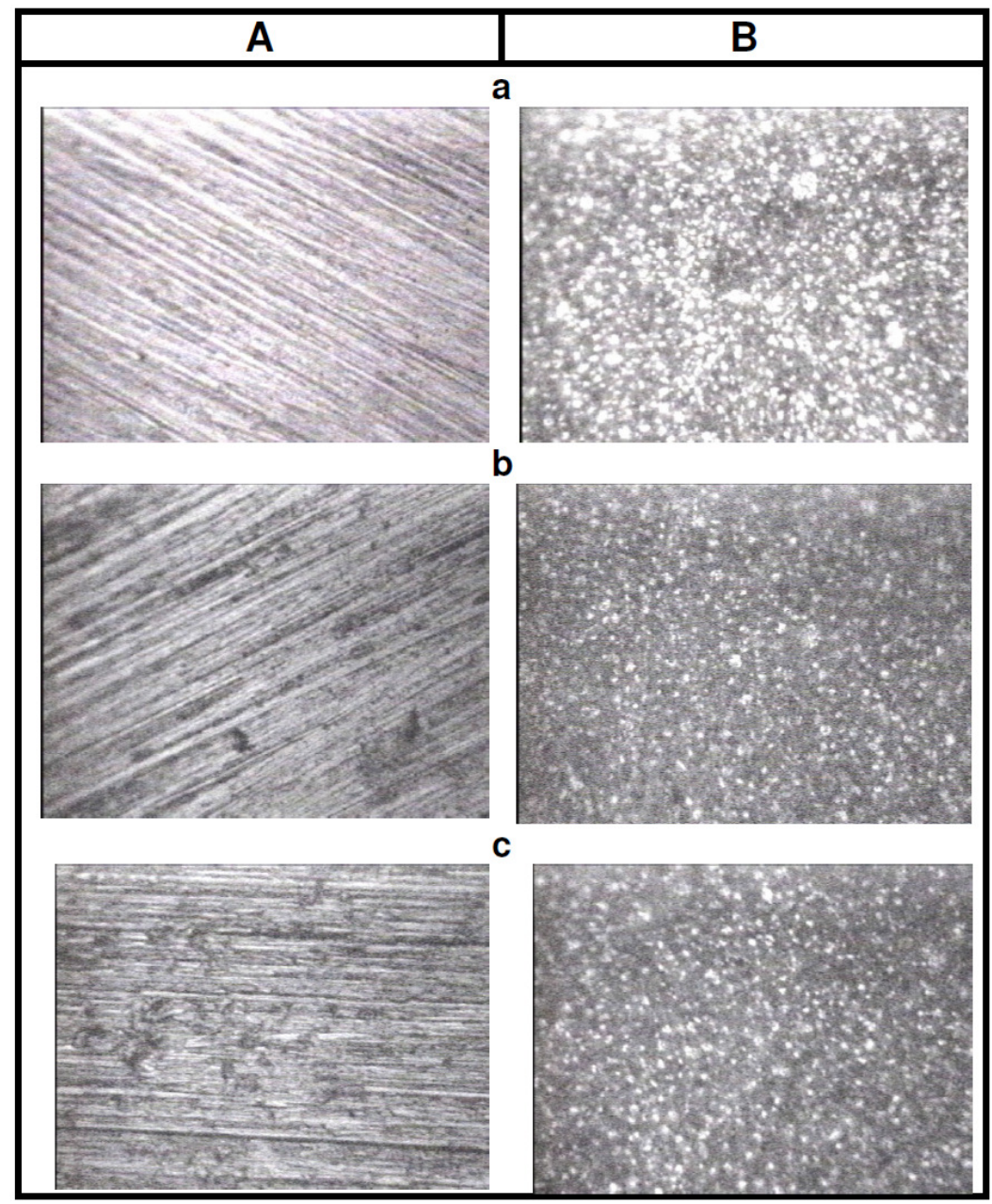

Figure 7. Optical microscopic photographs. (A) without alkaline etching, (B) with alkaline etching, (a) before dipping in $0.1 \mathrm{M} \mathrm{HCl}$, (b) after dipping for one hour in 0.1 $\mathrm{M} \mathrm{HCl}$ solution, (c) after dipping for one hour in $0.1 \mathrm{M} \mathrm{HCl}$ solution containing $50 \mathrm{ppm}$ of the plant extract.

\section{Conclusions}

Lupine extract can be used as corrosion inhibitor for aluminum in $0.1 \mathrm{M} \mathrm{HCl}$. Polarization and impedance results showed that lupine is more effective as inhibitor for non-etched compared to etched aluminum.

Fitting the data of adsorption of lupine at etched and non-etched aluminum surface in $0.1 \mathrm{M} \mathrm{HCl}$ to the kinetic-thermodynamic model shows stronger adsorption of the inhibitor at the non-etched aluminum surface compared to the etched aluminum. 
The optical photographs of aluminum obtained after alkaline etching indicated that the etching process reveals the surface of aluminum to be porous like in structure and decrease the number of active sites. This explains the lower efficiency of lupine as inhibitor to the acidic corrosion of etched aluminum.

\section{References}

1. Pourbaix M. Atlas of electrochemical equilibria in aqueous solutions. New York: Pergamon Press; 1966.

2. Dessai MN, Dessai MB, Shah CB, et al. Corros Sci. 1986;26:827.

3. Abd El-Maksoud SA. Corros Sci. 2002;44:803.

4. Ajmal M, Mideen AS, Quraishi MA. Corros Sci. 1994;36:79.

5. Raja PB, Sethuraman MG. Mater Lett. 2008;62:113.

6. El Hosary AA, Saleh RM, Shams El Din AM. Corros Sci. 1972;12:897.

7. Avwiri GO, Lgho FO. Mater Lett. 2003;57:3705.

8. Oguzie EE, Onuchukwu AI, Okafor PC, et al. Pig Resin Techn. 2006;35:63.

9. El-Etre AY. Corros Sci. 2003;45:2485.

10. Oguzie E.E. Corros Sci. 2007;49:1527.

11. Umoren SA, Obot IB, Ebenso EE, et al. Desalination. 2009;247:561.

12. Vega R, Gutierrez MP, Sanz C, et al. Ind Crop Prod. 1996;5:141.

13. Tsiodras S, Shin RK, Christian M, et al. Ann Emerg Med. 1999;33:715.

14. Abdel-Gaber AM, Abdel-Nabey BA, Saadawy M. Mater Corros. 2012;63:161.

15. Abdel-Naby BA, Abdullatef OA, Abdel-Gaber AM, et al. Int J Electrochem Sci. 2012;7:5864.

16. Abdel-Naby BA, Abdullatef OA, Abdel-Gaber AM, et al. Int J Electrochem Sci. 2014;9:1163.

17. Abdullatef OA, Shaker MA, Esmail G. Bull Fac Sci Alex Univ. 2013;48. Accepted.

18. Hegazy MA, Badawi AM, Abd El Rehim SS, et al. Corros Sci.2013;69:110.

19. El-Hosary AA, Saleh MR, Shams El-Din AM. Corros Sci. 1972;12:897

20. Amin MA, Abd El Rehim SS, El-Lithya AS. Corros Sci. 2010;52:3099.

21. Safak S, Duran B, Yurt A, et al. Corros Sci. 2012;54:251.

22. Khaled KF. Mater Chem Phys. 2008;112:290.

23. Behpour M, Ghoreishi SM, Mohammadi N, et al. Corros Sci. 2010;52:4046.

24. El-Awady AA, Aziz SG. Electochem Soc. 1992;139:2149.

25. El-Awady A, Abd El-Nabey BA, Aziz G, et al. Int J Chem. 1990:1169.

26. Emregul KC, Aksut AA. Corros Sci. 2000;42:2051. 